\title{
Implementasi Fuzzy C-Means dan Possibilistik C- Means Pada Data Performance Mahasiswa
}

\author{
Gadis Retno Apsari ${ }^{1}$, Mohammad Syaiful Pradana ${ }^{2}$, Novita Eka Chandra ${ }^{3}$ \\ ${ }^{1}$ Universitas Islam Darul Ulum Lamongan, gadisretnoapsari57@gmail.com \\ ${ }^{2}$ Universitas Islam Darul Ulum Lamongan, syaifulp@unisda.ac.id \\ ${ }^{3}$ Universitas Islam Darul Ulum Lamongan, novitaeka@unisda.ac.id
}

\begin{abstract}
Students are the most important component in a university, especially private universities especially Universitas Islam Darul 'ulum (Unisda) Lamongan. One of the most important roles of students for higher education is achievement. This study aims to determine the role of Fuzzy Clustering in classifying student performance data. The data includes GPA (Grade Point Average), ECCU (ExtraCurricular Credit Unit), attendance, and students' willingness to learn. So that groups of students who have the potential to have achievements can be identified. In this case, the grouping of student performance data uses Fuzzy Clustering by applying the Fuzzy C-Means (FCM) and Possibilistic C-Means (PCM) algorithms with the help of Matlab. In the FCM algorithm, the membership degree is updated so as to produce a minimum objective function value. Meanwhile, the PCM algorithm uses a $\mathrm{T}$ matrix, which shows the peculiarities of the data which are also based on minimizing the objective function.
\end{abstract}

Keywords: Students Performance Data, Fuzzy Clustering, Fuzzy C-Means (FCM), Possibilistic C-Means (PCM).

\begin{abstract}
Abstrak Mahasiswa merupakan komponen terpenting dalam sebuah Perguruan Tinggi terutama Perguruan Tinggi Swasta seperti Universitas Islam Darul 'ulum (Unisda) Lamongan. Salah satu peranan terpenting mahasiswa untuk perguruan tinggi adalah prestasi. Penelitian ini bertujuan untuk mengetahui peranan Fuzzy Clustering dalam mengelompokkan data performance mahasiswa. Data tersebut meliputi IPK (Indeks Prestasi Kumulatif), SKEK (Satuan Kredit Ekstra Kurikuler), presensi, dan kemauan belajar mahasiswa. Sehingga kelompok mahasiswa yang berpotensi memiliki prestasi dapat diketahui. Dalam hal ini pengelompokan data performance mahasiswa menggunakan Fuzzy Clustering dengan menerapkan algoritma Fuzzy C-Means (FCM) dan Possibilistic C-Means (PCM) dengan bantuan Matlab. Pada algoritma FCM, derajat keanggotaan diupdate sehingga menghasilkan nilai fungsi objective yang minimum. Sedangkan algoritma PCM menggunakan suatu matriks $T$, yang menunjukkan kekhasan dari suatu data juga didasarkan pada minimisasi fungsi obyektif.
\end{abstract}

Kata kunci: Data Performance Mahasiswa, Fuzzy Clustering, Fuzzy C-Means (FCM), Possibilistic C-Means (PCM). 


\section{Pendahuluan}

Mahasiswa merupakan komponen terpenting dalam sebuah Perguruan Tinggi terutama Perguruan Tinggi Swasta seperti Universitas Islam Darul 'ulum (Unisda) Lamongan. Salah satu peranan terpenting mahasiswa untuk perguruan tinggi adalah prestasi. Peranan mahasiswa dilingkungan Perguruan Tinggi sangatlah dibutuhkan. Terlebih jika mahasiswa mempunyai kemauan yang tinggi dalam menuntut ilmu, sehingga dapat mengharumkan nama Perguruan Tinggi.

Hal yang perlu dilakukan untuk mengetahui mahasiswa berprestasi tersebut dengan cara mengelompokkan mahasiswa berdasarkan aspek -aspek kemahasiswaan seperti: IPK (Indeks Prestasi Kumulatif), SKEK (Satuan Kredit Ekstra Kurikuler), presensi kehadiran dan kemauan belajar mahasiswa. Pengelompokkan data bertujuan untuk mengetahui kelompok mahasiswa yang berpotensi untuk menjadi mahasiswa berprestasi.

Clustering adalah suatu alat untuk analisa data yang memecahkan permasalahan penggolongan. Suatu algoritma clustering dikatakan sebagai algoritma fuzzy clustering jika dan hanya jika algoritma tersebut menggunakan parameter strategi adaptasi secara soft competitive (non - crisp) [1]. Sebagian besar algoritma fuzzy clustering didasarkan atas optimasi fungsi obyektif atau modifikasi dari fungsi obyektif tersebut. Dalam hal ini pengelompokan data performance mahasiswa menggunakan Fuzzy Clustering dengan menerapkan algoritma Fuzzy C-Means (FCM) dan Possibilistic C-Means (PCM) dengan bantuan Matlab.

Penelitian ini bertujuan untuk mengetahui peranan Fuzzy Clustering dalam mengelompokkan data performance mahasiswa. Data yang sudah dikelompokkan maka diharapkan data tersebut akan mempermudah Perguruan Tinggi dalam mengetahui potensi mahasiswa berdasarkan kriteria yang diberikan.

\section{Tinjauan Pustaka}

Clustering merupakan teknik multivariat yang bertujuan untuk mengelompokkan atau mengcluster suatu objek menjadi beberapa bagian berdasarkan karakteristik dan kemungkinan yang sama sehingga setiap anggota pada satu cluster mempunyai kesamaan yang tinggi dan sangat berbeda pada satu cluster dengan cluster yang lain. Clustering biasanya diterapkan pada pengambilan keputusan, image segmentation, klasifikasi susunan gambar atau pola. Pada analisis cluster terdapat dua tipe pengelompokkan yaitu crisp clustering dan fuzzy clustering sedangkan menurut [2] pada fuzzy clustering terdapat partisi possibilistik (possibilistic partition). Pada proses pengelompokkan crisp clustering pembentukan kelompok dilakukan hingga setiap objek berada tepat pada satu kelompok dan mengabaikan kemungkinan jika suatu objek tersebut berada pada kelompok lain [3]. Akan tetapi jika objek yang akan dikelompokkan tersebut berada pada dua kelompok atau lebih maka di perlukan suatu metode yaitu fuzzy clustering. Fuzzy clustering merupakan metode pengelompokkan suatu objek dengan mempertimbangkan derajat keanggotaan pada himpunan fuzzy sebagai dasar pembobotan [4].

Metode fuzzy clustering merupakan metode untuk mengcluster atau menentukan kelompok yang optimal dalam suatu ruang vektor yang jaraknya didasarkan pada bentuk normal Euclidian. Setiap data dilengkapi dengan derajat 
keanggotaan himpunan fuzzy sehingga data mempunyai nilai kemungkinan untuk bisa bergabung pada setiap kelompok yang ada sehingga, data tidak terfokus pada satu kelompok saja akan tetapi juga mempunyai kemungkinan untuk menjadi anggota kelompok yang lain dengan derajat keanggotaan yang berbeda-beda [5]. Adapun yang termasuk pada metode fuzzy clustering yaitu Fuzzy C-Means (FCM).

Pada fuzzy clustering terdapat partisi possibilistik (possibilistic partition). Partisi possibilistik (possibilistic partition) merupan metode untuk mengcluster dengan menjelaskan possibilistic dan probabilistic yang diintepretasikan pada matriks kekhasan atau typicality value. Possibilistic partition merupakan metode untuk menentukan kelompok yang optimal dalam suatu ruang vektor yang jaraknya didasarkan pada bentuk normal Euclidian. Pada possibilistic partition jumlah nilai anggota suatu data pada semua cluster tidak harus satu akan tetapi untuk menjamin suatu data menjadi anggota paling tidak satu cluster maka diharuskan ada nilai keanggotaan yang lebih dari nol. Selain menunjukkan nilai kemungkinan dari suatu data cenderung pada kelompok tertentu, possibilistic partition juga menunjukkan nilai yang jauh dari cluster tertentu. Semakin tinggi nilai possibilistic pada suatu data maka semakin besar kemungkinan suatu data masuk pada kelompok tertentu. Adapun metode yang termasuk possibilistic partition ialah Possibilistic C-Means (PCM) dan campuran antara Fuzzy C-Means (FCM) pada fuzzy clustering dengan Possibilistic C-Means (PCM) pada possibilistic partition ialah metode Possibilistic Fuzzy C-Means (PFCM) [2].

\section{Metode Penelitian}

\subsection{Fuzzy C - Means (FCM)}

Fuzzy C - Means (FCM) adalah suatu teknik pengclusteran data yang mana kebedaan tiap - tiap titik data dalam sebuah cluster ditentukan oleh derajat keanggotaan. Teknik ini pertama kali diperkenalkan oleh Jim Bezdek pada tahun 1981. Konsep dasar Fuzzy $C$ - Means, pertama kali adalah menentukan pusat cluster, yang akan menandai lokasi rata-rata untuk tiap-tiap cluster. Pada kondisi awal, pusat cluster ini masih belum akurat. Tiap-tiap titik data memiliki derajat keanggotaan tiap-tiap titik data secara berulang, maka akan dapat dilihat bahwa pusat cluster akan bergerak menuju lokasi yang tepat. Perulangan ini didasarkan pada minimalisasi fungsi obyektif yang menggambarkan jarak dari titik data yang diberikan ke pusat cluster yang terbobot oleh derajat keanggotaan titik data tersebut.

Algoritma Fuzzy C - Means (FCM) sebagai berikut:

1. Input data yang akan di cluster $X$, berupa matriks berukuran $n \times m(n=$ jumlah sampel data, $m=$ atribut setiap data). $X_{i j}=$ data sampel ke- $i(i=$ $1,2, \ldots, n)$, atribut ke- $j(j=1,2, \ldots, m)$.

2. Tentukan:

a. Jumlah cluster $\quad=c$

b. Pangkat $=w$

c. Maksimum iterasi $=$ MaxIter

d. Error terkecil $=\xi$

e. Fungsi obyektif awal $=P 0=0$

f. Iterasi awal $\quad=t=1$ 
3. Bangkitkan bilangan random $\mu_{i k}, i=1,2, \ldots, n ; k=1,2, \ldots, c$; sebagai elemen-elemen matriks partisi awal $U$.

dengan $j=1,2, \ldots, n$. Hitung:

$$
Q_{j}=\sum_{k=1}^{c} \mu_{i k}
$$

$$
\mu_{i k}=\frac{\mu_{i k}}{Q_{j}}
$$

4. Hitung pusat cluster ke- $k: V_{k j}$, dengan $k=1,2, \ldots, c$; dan $j=1,2, \ldots, m$

$$
V_{k j}=\frac{\sum_{i=1}^{n}\left(\left(\mu_{i k}\right)^{w} \cdot X_{i j}\right)}{\sum_{i=1}^{n}\left(\mu_{i k}\right)^{w}}
$$

5. Hitung perubahan matriks partisi:

$$
\mu_{i k}=\frac{\left[\sum_{j=1}^{m}\left(X_{i j}-V_{k j}\right)^{2}\right]^{\frac{-1}{w-1}}}{\sum_{k=1}^{c}\left[\sum_{j=1}^{m}\left(X_{i j}-V_{k j}\right)^{2}\right]^{\frac{-1}{w-1}}}
$$

6. Cek kondisi berhenti:

a. Jika: $(|P t-P t-1|<\xi)$ atau $(t>$ MaxIter $)$ maka berhenti;

b. Jika tidak: $t=t+1$, ulangi langkah ke-4.

\subsection{Possibilistic C-Means (PCM)}

Possibilistic $C-$ Means (PCM) menggunakan suatu matriks $T$, yang menunjukkan kekhasan dari suatu data. Possibilistic $C$ - Means (PCM) juga didasarkan pada minimisasi fungsi obyektif yang diberikan. Nilai keanggotaan pada setiap titik data dapat di interprestasikan pada derajat kesesuaian atau derajat kemungkinan.

Algoritma Possibilistic C-Means (PCM) diberikan sebagai berikut [6].

1. Tentukan:

a. Matriks $X$ berukuran $n \times m$, dengan $n=$ jumlah data yang akan di cluster, dan $m=$ jumlah variabel.

b. Jumlah cluster $=c$

c. Pangkat $=w$

d. Maksimum iterasi $=$ MaxIter

e. Error terkecil $=\xi$

f. Koefisien untuk menghitung $\gamma=K$

2. Panggil algoritma FCM, hasil akhir dari proses clustering, yaitu matriks partisi $U$ dan pusat cluster $V$, gunakan untuk menghitung:

$$
\gamma_{i}=K \frac{\sum_{k=1}^{n}\left(\mu_{i k}\right)^{w}\left(d_{i k}\right)^{2}}{\sum_{k=1}^{n}\left(\mu_{i k}\right)^{w}}
$$

dengan:

$$
d_{i k}=d\left(x_{k}-v_{i}\right)=\left[\sum_{j=1}^{m}\left(X_{k j}-V_{i j}\right)\right]^{\frac{1}{2}}
$$

3. Tetapkan iterasi awal $t=1$, dan $\Delta=1$;

4. Hitung matriks kekhasan, $T$, sebagai berikut:

$$
t_{i k}=\left[1+\left(\frac{\left(d_{i k}\right)^{2}}{\gamma i}\right)^{\frac{1}{w-1}}\right]^{-1} ; 1 \leq i \leq C ; 1 \leq j \leq m
$$


5. Hitung pusat cluster $V$, untuk setiap cluster:

\section{Hasil dan Pembahasan}

\subsection{Pengelompokkan Menggunakan Algoritma Fuzzy C-Means (FCM)}

Data-data mahasiswa dikelompokkan menjadi empat cluster. Pada Langkah pertama diberikan nilai awal untuk jumlah cluster, pangkat, maksimum iterasi dan kriteria pemberhentian sebagai berikut:

1. Matriks $X$ berukuran $32 \times 4$

2. Jumlah cluster yang akan dibentuk $=c=4$

3. Pangkat $=w=2$

4. Maksimum iterasi $=$ MaxIter $=100$

5. Kriteria pemberhentian $=\xi=10^{-6}$

Setelah ditetapkan nilai awal pada langkah pertama, langkah selanjutnya yaitu bangkitkan bilangan random $\mu_{i k}$ sebagai elemen-elemen matriks partisi awal $U$. Selanjutnya menghitung pusat cluster. Dari hasil pengelompokkan menggunakan diperoleh pusat cluster $V$ terakhir pada iterasi ke -8 , sebagai berikut:

$$
V=\begin{array}{cccc}
3.76 & 3.56 & 3.77 & 3.74 \\
14.99 & 3.30 & 15.66 & 15.50 \\
91.75 & 89.54 & 90.20 & 92.65 \\
60.18 & 58.67 & 59.95 & 59.89
\end{array}
$$

Nilai pada kolom ke $-1,2,3$, dan 4 adalah nilai dari $C 1, C 2, C 3$ dan $C 4$. Nilai pada baris ke -1 adalah nilai IPK, nilai pada baris ke -2 adalah perolehan jumlah SKEK, nilai pada baris ke -3 adalah jumlah presentase presensi dan nilai pada baris ke -4 adalah hasil presentase kemauan belajar. Nilai cluster $V$ didapatkan berupa matriks berukuran $4 \times 4$ karena, jumlah cluster (c) yang dibentuk $=4$ dan jumlah indikator aspek-aspek kemahasiswaan yang digunakan $=4$, diantaranya nilai IPK, jumlah SKEK, presentase presensi dan presentase kamauan belajar.

Langkah selanjutnya memperbaiki matriks partisi. Pada iterasi ke -8 , nilai mutlak terbesar antara $U^{8}$ dan $U^{7}$ adalah $\Delta=1.3944 e-007<\xi$, sehingga proses berhenti dan menghasilkan matriks partisi baru.

Dari hasil running program dapat dilihat kecenderungan suatu data untuk masuk pada masing-masing cluster. Mahasiswa ke 3, 4, 5, 6, 7, 8, 9, 10, 11, 12, $13,14,15,16,18,19,20,21,23,24,25,26,27,28,29,30$, dan 32 masuk dalam cluster pertama. Mahasiswa ke 1 dan 17 masuk dalam cluster kedua. Mahasiswa ke 2, 13, 22 dan 31 masuk dalam cluster keempat. Tidak ada mahasiswa yang masuk dalam cluster ketiga.

Selanjutnya, dari pusat cluster $V$, dapat disimpulkan bahwa:

a. Secara Numeris

1) Cluster I adalah mahasiswa yang memiliki rata-rata nilai IPK 3.76 , jumlah SKEK 14.99, presentase kehadiran 91.75\% dan kemauan belajar $60.18 \%$. 
2) Cluster II adalah mahasiswa yang memiliki rata-rata nilai IPK 3.56 , jumlah SKEK 3.30, presentase kehadiran 89.54\% dan kemauan belajar $58.67 \%$.

3) Cluster III adalah mahasiswa yang memiliki rata-rata nilai IPK 3.77, jumlah SKEK 15.66, presentase kehadiran 90.20\% dan kemauan belajar $59.95 \%$.

4) Cluster IV adalah mahasiswa yang memiliki rata-rata nilai IPK 3.74, jumlah SKEK 15.50, presentase kehadiran 92.65\% dan kemauan belajar $59.89 \%$.

b. Secara Linguistik

Untuk membuat kesimpulan secara linguistik, menentukan keriteria bentuk lingustik berdasarkan kategori yang dijelaskan pada Tabel 1 berikut.

Tabel 1. Kriteria Bentuk Linguistik

\begin{tabular}{ccccc}
\hline IPK & SKEK & Presensi & $\begin{array}{c}\text { Kemauan } \\
\text { Belajar }\end{array}$ & Kategori \\
\hline $\mathrm{x}>3.70$ & $\mathrm{x}>15$ & $\mathrm{x}>90$ & $\mathrm{x}>60$ & Tinggi \\
$3.00<\mathrm{x} \leq 3.70$ & $5<\mathrm{x} \leq 15$ & $50<\mathrm{x} \leq 90$ & $0<\mathrm{x} \leq 60$ & Sedang \\
$\mathrm{x} \leq 3.00$ & $\mathrm{x} \leq 5$ & $\mathrm{x} \leq 50$ & $\mathrm{x} \leq 30$ & Rendah \\
\hline
\end{tabular}

Tabel 2. Hasil Kesimpulan Linguistik pada Algoritma FCM

\begin{tabular}{cccccc}
\hline No. & Cluster & IPK & SKEK & Presensi & $\begin{array}{c}\text { Kemauan } \\
\text { Belajar }\end{array}$ \\
\hline 1 & Cluster 1 & 3.76/Tinggi & 14.99/Sedang & 91.75/Tinggi & 60.18/Tinggi \\
2 & Cluster 2 & 3.56/Sedang & 3.30/Rendah & 89.54/Sedang & 58.67/Sedang \\
3 & Cluster 3 & 3.77/Tinggi & 15.66/Tinggi & 90.20/Tinggi & 59.95/Sedang \\
4 & Cluster 4 & 3.74/Tinggi & 15.50/Tinggi & 92.65/Tinggi & 59.89/Sedang \\
\hline
\end{tabular}

Dapat disimpulkan bahwa:

1. Cluster I adalah mahasiswa yang memiliki rata-rata nilai IPK tinggi, jumlah SKEK sedang, presentase kehadiran tinggi dan kemauan belajar tinggi.

2. Cluster II adalah mahasiswa yang meemiliki rata-rata nilai IPK sedang, jumlah SKEK rendah, presentase kehadiran sedang dan kemauan belajar sedang.

3. Cluster III adalah mahasiswa yang rata-rata memiliki nilai IPK tinggi, jumlah SKEK tinggi, presentase kehadiran tinggi dan kemauan belajar sedang.

4. Cluster IV adalah mahasiswa yang rata-rata memiliki nilai IPK tinggi, jumlah SKEK tinggi, presentase kehadiran tinggi dan kemauan belajar sedang.

Dari kesimpulan secara numeris dan linguistik maka dapat diketahui bahwa antara cluster III dan cluster IV memiliki kriteria yang sama atau pola yang sama. 


\subsection{Pengelompokkan Menggunakan Algoritma Possibilistic C-Means (PCM)}

Data-data tersebut akan dikelompokkan menjadi empat cluster. Pada pertama diberikan nilai awal untuk jumlah cluster, pangkat, maksimum iterasi, kriteria pemberhentian dan koefisien untuk menghitung $\gamma=K$ sebagai berikut:

a. Matriks $X$ berukuran $32 \times 4$

b. Jumlah cluster yang akan dibentuk $=c=4$

c. Pangkat $=w=2$

d. Maksimum iterasi $=$ MaxIter $=100$

e. Kriteria pemberhentian $=\xi=10^{-6}$

f. Koefisien untuk menghitung $\gamma=K=1$

Selanjutnya, panggil algoritma FCM, hasil akhir dari proses clustering yaitu matriks partisi $U$ dan pusat cluster $V$ dan tetapkan iterasi awal $t=1$ dan $\Delta=1$. Setelah melalui proses iterasi pada Matlab maka didapatkan matriks kekhasan $T$. Dari hasil Matlab diperoleh pusat cluster $V$ terakhir pada iterasi ke-12, sebagai berikut:

$$
V=\begin{array}{cccc}
3.72 & 3.26 & 3.74 & 3.75 \\
13.09 & 1.15 & 13.70 & 15.42 \\
91.79 & 86.23 & 90.83 & 91.33 \\
59.73 & 62.74 & 59.62 & 61.04
\end{array}
$$

Nilai pada kolom $k e-1,2,3$, dan 4 adalah nilai dari $C_{1}, C_{2}, C_{3}$ dan $C_{4}$. Nilai pada baris $k e-1$ adalah nilai IPK, nilai pada baris $k e-2$ adalah perolehan jumlah SKEK, nilai pada baris $k e-3$ adalah jumlah presentase presensi dan nilai pada baris $k e-4$ adalah hasil presentase kemauan belajar. Nilai cluster $V$ didapatkan matriks berukuran $4 \times 4$ karena, jumlah cluster $(c)$ yang dibentuk $=4$ dan jumlah indikator aspek-aspek kemahasiswaan yang digunakan $=4$, diantaranya nilai IPK, jumlah SKEK, presentase presensi dan presentase kamauan belajar.

Dari hasil pengelompokkan menggunakan Matlab berhenti pada iterasi ke12. Nilai mutlak terbesar antara $T^{12}$ dan $T^{11}$ adalah $\Delta=9.9440 e-007<\xi$, sehingga proses iterasi dihentikan, karena sudah konvergen dan menghasilkan matriks kekhasan $T$ pada iterasi terakhir.

Dari hasil running program dapat dilihat kecenderungan suatu data untuk masuk pada masing - masing cluster seperti terlihat pada Tabel 4.3. Data ke $3,4,8,9,10,11,12,13,14,15,16,18,19,20,21,22,25,26,27,29$, dan 32 cenderung untuk masuk cluster yang pertama. Data ke - 1,17 dan 24 cenderung masuk ke cluster yang kedua. Data $k e-5,6,7,23,28$, dan 30 cenderung masuk ke cluster ketiga dan data $k e-2$ dan 31 cenderung masuk ke cluster yang ke empat.

Selanjutnya, dari pusat cluster $V$ dapat disimpulkan bahwa:

a. Secara Numeris

1. Cluster I adalah mahasiswa yang memiliki rata-rata nilai IPK 3.72, jumlah SKEK 13.09, presentase kehadiran 91.79\% dan kemauan belajar 59.73\%. 
2. Cluster II adalah mahasiswa yang rata-rata memiliki nilai IPK 3.26, jumlah SKEK 1.15, presentase kehadiran $86.23 \%$ dan kemauan belajar $62.74 \%$.

3. Cluster III adalah mahasiswa yang memiliki rata-rata nilai IPK 3.74, jumlah SKEK 13.70, presentase kehadiran 90.83\% dan kemauan belajar $59.62 \%$.

4. Cluster IV adalah mahasiswa yang memiliki rata-rata nilai IPK 3.75, jumlah SKEK 15.42, presentase kehadiran 91.33\% dan kemauan belajar $61.04 \%$.

b. Secara Linguistik

Tabel 3. Hasil Kesimpulan Linguistik pada Algoritma PCM

\begin{tabular}{ccccc}
\hline Cluster & IPK & SKEK & Presensi & $\begin{array}{c}\text { Kemauan } \\
\text { Belajar }\end{array}$ \\
\hline Cluster 1 & 3.72/Tinggi & 13.09/Sedang & 91.79/Tinggi & 59.73/Sedang \\
Cluster 2 & 3.26/Sedang & 1.15/Rendah & 89.23/Sedang & 62.74/Tinggi \\
Cluster 3 & 3.74/Tinggi & 13.70/Sedang & 90.83/Tinggi & 59.62/Sedang \\
Cluster 4 & 3.75/Tinggi & 15.42/Tinggi & 91.33/Tinggi & 61.04/Tinggi \\
\hline
\end{tabular}

Dapat disimpulkan bahwa:

1. Cluster I adalah mahasiswa yang memiliki rata - rata nilai IPK Tinggi, jumlah SKEK sedang, presentase kehadiran tinggi dan kemauan belajar sedang.

2. Cluster II adalah mahasiswa yang memiliki rata - rata nilai IPK sedang, jumlah SKEK rendah, presentase kehadiran sedang dan kemauan belajar tinggi.

3. Cluster III adalah mahasiswa yang memiliki rata - rata nilai IPK tinggi, jumlah SKEK sedang, presentase kehadiran tinggi dan kemauan belajar sedang.

4. Cluster IV adalah mahasiswa yang memiliki rata - rata nilai IPK tinggi, jumlah SKEK tinggi, presentase kehadiran tinggi dan kemauan belajar tinggi.

Dari kesimpulan secara numeris dan linguistik maka dapat diketahui bahwa cluster IV adalah cluster yang terbaik. Artinya mahasiswa pada cluster IV dapat dikatakan memiliki potensi dalam mengembangkan prestasi Perguruan Tinggi.

\section{Kesimpulan}

Pada algoritma FCM, derajat keanggotaan diupdate sehingga menghasilkan nilai fungsi objective yang minimum. Sedangkan algoritma PCM menggunakan suatu matriks $T$, yang menunjukkan kekhasan dari suatu data juga didasarkan pada minimisasi fungsi obyektif. Berdasarkan hasil running program, algoritma FCM membutuhkan iterasi sebanyak 8 dengan nilai $\Delta=1.3944 e-007$, sedangkan algoritma PCM membutuhkan iterasi sebanyak 12 dengan nilai $\Delta=$ 
9.9440e-007. Walaupun iterasi PCM yang dihasilkan lebih banyak dibandingkan FCM, namun hasil cluster PCM lebih tegas dibandingkan FCM.

\section{Daftar Pustaka}

[1] A. Baraldi and P. Blonda, "A survey of fuzzy clustering algorithms for pattern recognition. I," IEEE Trans. Syst. Man, Cybern. Part B, vol. 29, no. 6, pp. 778-785, 1999.

[2] S. Kusumadewi, S. Hartati, A. Harjoko, and R. Wardoyo, "Fuzzy multiattribute decision making (fuzzy madm)," Yogyakarta Graha Ilmu, pp. 7879, 2006.

[3] M. H. Fazel Zarandi and M. Zarinbal, "Image Segmentation: Type-2 Fuzzy Possibilistic C-Mean Clustering Approach," Int. J. Ind. Eng. Prod. Res., vol. 23, no. 4, pp. 245-251, 2012.

[4] A. Rohmatullah, D. Rahmalia, and M. S. Pradana, "Klasterisasi Data Pertanian di Kabupaten Lamongan Menggunakan Algoritma K-Means Dan Fuzzy C Means,” J. Ilm. Teknosains, vol. 5, no. 2, pp. 86-93, 2019.

[5] M. A. S. Devi, "Penerapan Fuzzy C-Means dan Fuzzy Substractive Clustering pada Desa dan Kelurahan di Kabupaten Jember Berdasarkan Indikator Kemiskinan,” 2014.

[6] N. R. Pal, K. Pal, J. M. Keller, and J. C. Bezdek, "A possibilistic fuzzy cmeans clustering algorithm," IEEE Trans. fuzzy Syst., vol. 13, no. 4, pp. 517-530, 2005. 